\title{
Implant Fracture: A Narrative Literature Review
}

\author{
Marco Tallarico ${ }^{1, *} \mathbb{C}$, Silvio Mario Meloni ${ }^{1}$, Chang-Joo Park ${ }^{2}$, Łukasz Zadrożny $^{3}{ }^{\mathbb{D}}$, Roberto Scrascia ${ }^{4}$ \\ and Marco Cicciù ${ }^{5}$
}

check for

updates

Citation: Tallarico, M.; Meloni, S.M.; Park, C.-J.; Zadrożny, Ł.; Scrascia, R.; Cicciù, M. Implant Fracture: A Narrative Literature Review. Prosthesis 2021, 3, 267-279. https:// doi.org/10.3390/prosthesis3040026

Academic Editor: Bruno Chrcanovic

Received: 21 August 2021

Accepted: 15 September 2021

Published: 22 September 2021

Publisher's Note: MDPI stays neutral with regard to jurisdictional claims in published maps and institutional affiliations.

Copyright: (c) 2021 by the authors. Licensee MDPI, Basel, Switzerland. This article is an open access article distributed under the terms and conditions of the Creative Commons Attribution (CC BY) license (https:// creativecommons.org/licenses/by/ $4.0 /)$.
1 Surgical, Micro-Surgical and Medical Science Department, University of Sassari, 07100 Sassari, Italy; melonisilviomario@yahoo.it

2 Division of Oral and Maxillofacial Surgery, Department of Dentistry, College of Medicine, Hanyang University, Seoul 04763, Korea; fastchang@hanyang.ac.kr

3 Department of Dental Propaedeutics and Prophylaxis, Medical University of Warsaw, 02-006 Warsaw, Poland; lzadrozny@wum.edu.pl

4 Independent Researcher, 74121 Taranto, Italy; roberto.scrascia@gmail.com

5 Department of Biomedical and Dental Sciences, Morphological and Functional Images, University of Messina, 98100 Messina, Italy; marco.cicciu@unime.it

* Correspondence: me@studiomarcotallarico.it; Tel.: +39-328-075-8769

\begin{abstract}
Implants fracture is a rare but possible complication that leads to implants failure after prostheses delivery. Mechanical properties play a key role in the failure of dental implant systems. The aim of this narrative review was to evaluate the existing evidence in identifying etiology risk factors for implants fracture. The focused question was to evaluate whether there was any possible factors influencing the fracture of dental implants. A literature search of papers written in English, published from 1967 to July 2021, and reporting incidence of implants fracture in human with at least 15 participants (and one year of follow-up) was conducted using PubMed database including MeSH and free text terms and filters. Selected manuscripts were analyzed and discussed. The outcomes were the incidence of implants failure due to a fracture and the associated risk factors. A total of 96 articles were initially selected, but only eight articles were included according to the search criteria (two systematic reviews and six retrospective evaluation). Incidence of implants fracture ranged from 0.2 to $2.3 \%$, with a mean value of $0.52 \%$. Poor implant planning, including implant design and diameter, and occlusal overloading, were the most common variables associated with implants fracture. Implant removal is the only possible treatment and hence prevention, including stability of the marginal bone loss, is mandatory.
\end{abstract}

Keywords: implant fracture; complications; implant removal; dental implants; failure

\section{Introduction}

Since the discovery of osseointegration by prof. Peter-Ingvar Brånemark, implantology has undergone a considerable evolution allowing the successful treatment of partial and complete edentulism [1]. High implant survival and success rate could also be expected thanks to the improvement of surface treatments, implant and prosthetic materials, and geometry of implant body [2]. However, while the implant procedure is deemed to be safe, having dental implants installed is a surgical procedure. As for any surgical procedure, some risks may be involved. Even if the percentage of patients who end up having problems after receiving implant surgery is small, there are some patients that experienced several major complications, both biological and mechanical. Within these, progressive infections, lack of osseointegration, and implant fractures lead to implants failures $[3,4]$.

Implant fracture is a possible, even if improbable, cause of implant failure, that occurs very rarely. Brånemark and co-workers, about forty-five years ago, firstly reported $0.8 \%$ of fractured implants [5]. Nevertheless, although implants were made on titanium grade one, mostly of the cases were complete arch restorations, that are less probable to fracture. 
Recently, according to a couple of review manuscripts, the prevalence of implant fracture was reported to be around $1.0-1.5 \%[6,7]$.

The use of a standard (from $3.75 \mathrm{~mm}$ to less than $5 \mathrm{~mm}$ ) and wide ( $5.0 \mathrm{~mm}$ or more) diameter implants [8] is generally recommended in the posterior area to ensure sufficient contact between the bone and the implant, and at the same time, to allow sufficient occlusal load resistance. However, it should be emphasized that a minimum of $1.5 \mathrm{~mm}$ between the implant and the adjacent tooth, and $3 \mathrm{~mm}$ between implants, is essential to support the interdental papillae and to achieve adequate esthetics, reducing crestal bone loss [9]. Moreover, a minimum thickness of about 1.5 to $2.0 \mathrm{~mm}$ of bone must surround the entire implant surface, including the buccal and palatal/lingual sites, to reduce the risk of bone fenestration [9]. For the latter, thin ridges or limited space are a challenge that require advanced surgical techniques (edentulous ridge expansions, guided bone regeneration, etc.). With the aim to reduce the overall treatment time, costs, and patients' morbidity, narrow or extra-narrow diameter implants of $\geq 3.0 \mathrm{~mm}$ to $\leq 3.75 \mathrm{~mm}$, or less than $3.0 \mathrm{~mm}$, respectively, were used. Indeed, when the amount of horizontal available bone is less than $5 \mathrm{~mm}$, the placement of mini $(3.5 \mathrm{~mm})$ or standard $(4 \mathrm{~mm})$ diameter implants without bone management procedures, can often lead to gingival recession, bone resorption, and in advanced cases, exposure and/or infection of the implants, with irreversible consequences for the implants survival and/or success rate [10]. Hence, the gold standard still remains horizontal guided bone regeneration.

Extra-narrow and narrow diameter implants are primarily indicated in the anterior area to replace mandibular incisors or maxillary lateral incisors. They are also indicated in case of reduced mesio-distal space, and/or thin vestibulo-lingual thickness [11], to allow implant placement in situations where there is not enough space for wider diameter implants. Thus, the need for bone augmentation procedures, or pre-prosthetic orthodontic tooth movement could be avoided. Nevertheless, narrow implants should be used in areas not subjected to high occlusal force, as indicated by the manufacturers. Hence, high risk of implant fracture may occur when extra-narrow and narrow implants are placed in premolar and molar area $[12,13]$.

In an effort to re-evaluate the clinical approach to extra-narrow and narrow diameter implants, the aim of this narrative review was to evaluate the existing evidence in identifying etiology risk factors for implants fracture. The present review was conducted as part of the 2nd Osstem AIC Italy Consensus Conference. Osstem AIC Italy is an independent, no profit, scientific community that provides implant education for dentists including consensus conferences [14]. The present group was assigned the task to review the current knowledge regarding the prevalence of implant fracture.

\section{Results}

A total of 96 articles were found according to the search criteria. After abstracts evaluation and duplicates removal, 22 articles were deemed useful for the aim of the present review. A manual search using personal contacts and references of published works allows to include another two articles, resulting in a total of 24 manuscripts. Finally, after full-text articles selection and reading, eight manuscripts were included according to the inclusion/exclusion criteria $[3,4,7,8,10,15-17]$. Of these, two were systematic reviews [3,15], and six were retrospective evaluations $[4,7,8,10,16,17]$. Relevant informations from each article were extracted and analyzed.

\subsection{Incidence of Implants Fracture}

Seven studies reported incidence of implant fracture [3,4,8,10,15-17]. Major of the studies reported an incidence of less than $1 \%[3,4,8,15,17]$. Higher value was reported by Stoichkov and co-workers [16]. In this study, 5 implants fractured from a total of 218 (percentage $2.3 \%$ ).

In a previous systematic review by Berglundh and co-workers in 2002 [3], evaluating 159 articles on complications in implantology, the incidence of implant fractures was less 
than $1 \%(0.08$ to $0.74 \%)$, in a period of five years. Later, in two studies the incidence of implant fracture was $1.40 \%$ [10], and $0.23 \%$, as reported by Sánchez-Pérez and co-workers in another literature review published on 2010 [15]. In a 2017 retrospective cohort study of Tabrizi and co-workers [4], 37 implants fractures were experienced out of a total of 18,700 implant $(0.2 \%)$. In the same year, another retrospective study by Chrcanovic and co-workers [8], reported an incidence of $0.44 \%$. Overall, the fractured implants were 44 out of 10,099 in a total of 2670 patients. A year later, Stoichkov and Kirov reported an incidence of dental implant fracture of $2.3 \%$ experienced in 101 patients with 218 dental implants followed for a period ranging between three to 10 years [16]. More recently, Implant fracture failure rate of $0.92 \%$ was reported by Dong-Woon Lee in a retrospective study published into 2019, on 5124 patients and with up to 12-year of follow-up [17]. Overall, the percentage of fractured implants was $0.52 \%$ (302 implants out of 57,646, Table 1).

Table 1. Percentage of implant fracture.

\begin{tabular}{cccc}
\hline Study & Fractured Implants & Total Implants & Percentage \\
\hline Berglundh et al. [3] & 19 & 7279 & $0.26 \%$ \\
Tabrizi et al. [4] & 37 & 18,700 & $0.2 \%$ \\
Chrcanovic et al. [8] & 44 & 10,099 & $0.44 \%$ \\
Gargallo-Albiol et al. [10] & 21 & 1500 & $1.40 \%$ \\
Sánchez-Pérez et al. [15] & 2 & 844 & $0.23 \%$ \\
Stoichkov et al. [16] & 5 & 218 & $2.3 \%$ \\
Lee et al. [17] & 174 & 19,006 & $0.92 \%$ \\
Grand total & $\mathbf{3 0 2}$ & $\mathbf{5 7 , 6 4 6}$ & $\mathbf{0 . 5 2 \%}$ \\
\hline
\end{tabular}

\subsection{Risk Factors for Implants Fracture}

Seven studies reported incidence of implants fracture $[3,4,7,8,10,16,17]$. According to Berglundh and co-workers [3], poor implant planning, implant-abutment misfit, and overloading were the most common reasons for implants fracture. Later, Tabrizi and co-workers reported as possible causes of implants fracture long lasting time, treated area, implant and prosthetic design [4]. For all of these variables, a statistically significant correlation was found. Risk of implant fracture was $0.38 / 1000$ and 1.46/1000 at the 1 - and 5 -year follow-up, respectively. Moreover, implant fractures occurred more often in the premolar and molar area $(94.6 \%)$. Finally, the incidence of implants fracture was higher for conical connection implants and for single screw-retained prostheses.

In agreement with these results, a larger retrospective evaluation by Chrcanovic and co-workers [8], reported a mean time before implant fracture of $95.1 \pm 58.5$ months, with half of the fractures occurred between two and eight years. The authors also identified five more possible influencing factors: high grade titanium (72.9\% reduced risk); bruxism (1819.5\% increased risk); adjacent to a cantilever ( $247.6 \%$ increased risk); implant length (22.3\% increased risk per $\mathrm{mm}$ ); and implant diameter (96.9\% less risk per $\mathrm{mm}$ ). In this retrospective study there was no statistically significant differences between prosthesis design. The chi-square statistic is 2.782 . The $p$-value is 0.594943 . The result is not significant at $p<0.05$. Data are reported in the Table 2 .

Table 2. Percentage of implant fracture according to the prosthetic design (by Chrcanovic et al. [8], modified).

\begin{tabular}{cccc}
\hline Prosthetic Design & Fractured Implants & Total Implants & Percentage \\
\hline Single crown & 6 & 1683 & $0.36 \%$ \\
Partial-fixed (2 to 6 units) & 12 & 2600 & $0.46 \%$ \\
Partial-fixed (7 to 10 units) & 1 & 371 & $0.27 \%$ \\
Full-arch fixed & 23 & 5055 & $0.45 \%$ \\
Overdenture & 2 & 293 & $0.68 \%$ \\
Grand total & $\mathbf{4 4}$ & $\mathbf{1 0 , 0 0 2}$ & $\mathbf{0 . 4 4 \%}$ \\
\hline
\end{tabular}


Higher incidence of implant fractures was established in the area of the molars and premolars. Based on the study by Gargallo-Albiol and co-workers [10], the onset of these complications occurs during the first two to three years after the functional load of the implants. Also in the study of Chrcanovic and co-workers [8], statistically significant difference was found for implant diameter. The chi-square statistic is 2.782 . The $p$-value is $<0.0001$. The result is significant at $p<0.05$. Data are reported in the Table 3 .

Table 3. Percentage of implant fracture according to the implant diameter (by Chrcanovic et al. [8], modified).

\begin{tabular}{cccc}
\hline Prosthetic Design & Fractured Implants & Total Implants & Percentage \\
\hline Narrow $(3.00-3.50 \mathrm{~mm})$ & 14 & 1038 & $1.35 \%$ \\
Regular (3.70-4.10 mm) & 30 & 8873 & $0.34 \%$ \\
Wide (4.20-5.00 mm) & 0 & 186 & $0 \%$ \\
Grand total & $\mathbf{4 4}$ & $\mathbf{1 0 , 0 9 7}$ & $\mathbf{0 . 4 4 \%}$ \\
\hline
\end{tabular}

In agreement with previous reports, Stoichkov and Kirov reported as most common causes associated with implant fracture, the implant design (e.g., diameter and length, biomaterial, and macro-design of the implant), physiologic or biomechanical occlusal overload, and incorrect operative and prosthetic planning [16].

In the retrospective study by Dong-Woon Lee [17], the implant diameter, location, history of bone graft, and microthread presence were significantly correlated with implant fractures. On the contrary, wide-diameter implants had a reduced fracture risk within 90 months, after which the diameter did not correlate with fractures. Implants placed in the anterior mandible had a lower fracture risk within 90 months; mandibular premolar implants corresponded with a lower risk up to 90 months on function. Implants without a history of bone graft or without microthreads were more likely to fracture throughout the follow-up time.

In two retrospective studies the percentage of implants fracture, for different implant companies and systems were reported $[8,17]$. Even if a direct comparison is not possible, all of the major implant brands fractured with percentage from $0.74 \%$ (Osstem TSIII with conical connection) to $2.57 \%$ (Nobel replace with butt internal connection) $[8,17]$.

\section{Discussion}

Implants fracture is a rare but not exceptional biomechanical complication that may occur with a significant incidence. During the past few years, several studies reported incidence of implant fracture within a range of 0.2 to $2.3 \%$. In the present narrative review, the overall incidence of implant fracture is $0.52 \%$. This data are slightly lower than previous review manuscripts, where, the prevalence of implant fracture was reported to be around $1.0-1.5 \%[6,7]$. The reason for better value should be due to the improvement in implant design and materials.

Nevertheless, dental implants market is growing and it is expected to increase from USD 7222 million in 2020 to USD 11,801 million by 2026 [18]. The American Academy of Implant Dentistry provides evidence of growth in the industry stating that the number of people getting implants in the United States increased by 500,000 a year [19]. Reasons for dental market growing could be rise on geriatric population, dental diseases, along with the misconception that dental implants may increase long lasting success, and aesthetics of dental restorations. It means that, proportionally, biological and mechanical complications, including several implants fractures, could be expected yearly.

Implants fracture, even if rare, is a serious complication, which leads to implant and prosthesis failure. In contrast to peri-implantitis, for which several approaches have been proposed, depending on the severity of the bone loss around the implant, the only possible treatment of a fractured implant is its removal. Hence, its prevention is mandatory.

There are still limited and conflicted data available regarding possible associations between implants fracture and some risk factors. Various biomechanical issues were suggested by several authors. Implant and prosthetic design (implants diameter and 
length, and type of prosthetic restorations) were the most common reasons suggested in four studies $[4,8,16,17]$. Within these, implant diameter is the most significant variable, with an estimated risk up to three times higher for narrow implants placed in molar area. Tabrizi and co-workers reported higher incidence of implants fracture for single crown [4]. On the other hands, no difference was found in the retrospective study by Chrcanovic and co-workers [8]. These authors also reported that risk for implants fracture increases over time, as expected due to metal fatigue by overloading. Berglundh and co-workers [3], specifically suggested that implant-abutment misfit and overloading were the most common reasons for implants fracture. On the same page, Stoichkov and Kirov reported biomechanical overloading as one of the most common variables associated with implant fracture [16]. In addition, Chrcanovic and co-workers [5] identified titanium presence of cantilever, parafunctional activities, such as bruxism (e.g., teeth clenching and grinding), narrow implant diameter as major variables that may cause overloading, and therefore, they were associated with higher risk of implant fracture. Last but not the least, Berglundh, Stoichkov, and co-workers [3,16], pointed at the poor implant planning as major reason for failure. It is the author's opinion that poor implant planning is the base of everything. Tridimensional implant position, diameter and number of implants, their inclination, accurate implant/abutment selection, as well as, occlusion management are mandatory to ensure long lasting survival and success of an implant-supported restoration.

Localization of the implants, diameter and number of implants, their inclination to the sagittal and transverse planes, may increase stress on the peri-implant cortical bone.

According to Tabrizi et al. [4], the incidence of implants fracture was higher for conical connection implants and for single screw-retained prostheses. Screw-loosening and marginal bone loss were often associated with implant fracture [20]. Both complications may lead the implant-abutment complex to undergo increased horizontal forces that may finally cause implants fracture. Though it is obvious, screw loosening depends by technical reasons, several variables were associated to increased peri-implant bone loss. Of these, poor treatment planning, including wrong implants position, crown-to-implant ration, and overloading were associated with higher risk of marginal bone loss [21,22]. Very often standard or narrow diameter implants are used in the molar area to avoid bone reconstruction. It is the authors' opinion that, in case when guided bone regeneration is not indicated, tissue level implants of standard diameter should be used. Tissue level implants with wider implant neck present strong resistance at the implant-abutment complex. In fact, data from the present narrative review strongly suggested proportional increase in diameter/strength in case of molar and premolar teeth must to be replaced. Because $3.5 \mathrm{~mm}$ diameter implants are weak, their usage should be limited to mandibular anterior teeth or maxillary lateral incisor area where occlusal load is not heavy. The $4.0 \mathrm{~mm}$ diameter implants are the first choice in maxillary anterior teeth or both premolar teeth area. Finally, minimum size of $4.5 \mathrm{~mm}$ of diameter is recommended when replacing molar teeth. Nevertheless, great disparity is reported when the implant is fully submerged in bone or is partially exposed by bone resorption [22]. In many cases, some preliminary signals could be expected: typically screw loosening, sometimes even fracture of the passing screw. Crown-to-implant-ratio seems to be a more relevant variable when considering the resistance to fracture of implants, since significant reductions were observed when unfavorable crown-to-implant-ratio subgroups (2.5:1 and 3:1) were compared with the 2:1 samples [22].

Dental implant companies are working on stronger resistance of dental implants. In fact, according to Chrcanovic and co-workers [8], a high grade of titanium was a protective factor, as well as, wider implant diameter. The results of a prospective randomized clinical trial suggest that narrow Ti-Zr implant were comparable with standard-diameter conventional titanium implants in the sort term [23], even if fractured Ti-Zr implant was reported [24]. Unfortunately, most of available data derived from in vitro research, retrospective study, or previous reviews [25-28]. 
Implants fracture is an untreatable condition. There are several tools that may help clinician to remove the implant. However, fractured implant often presented damaged implant-abutment connection, hence, implant retrieval tools/kits (Figures 1-4) may not work. In cases implant is severely damaged and/or the residual osseointegration is very strong, such us in the mandible, the only possibility is to use a trephine burs (Figures 5-10).

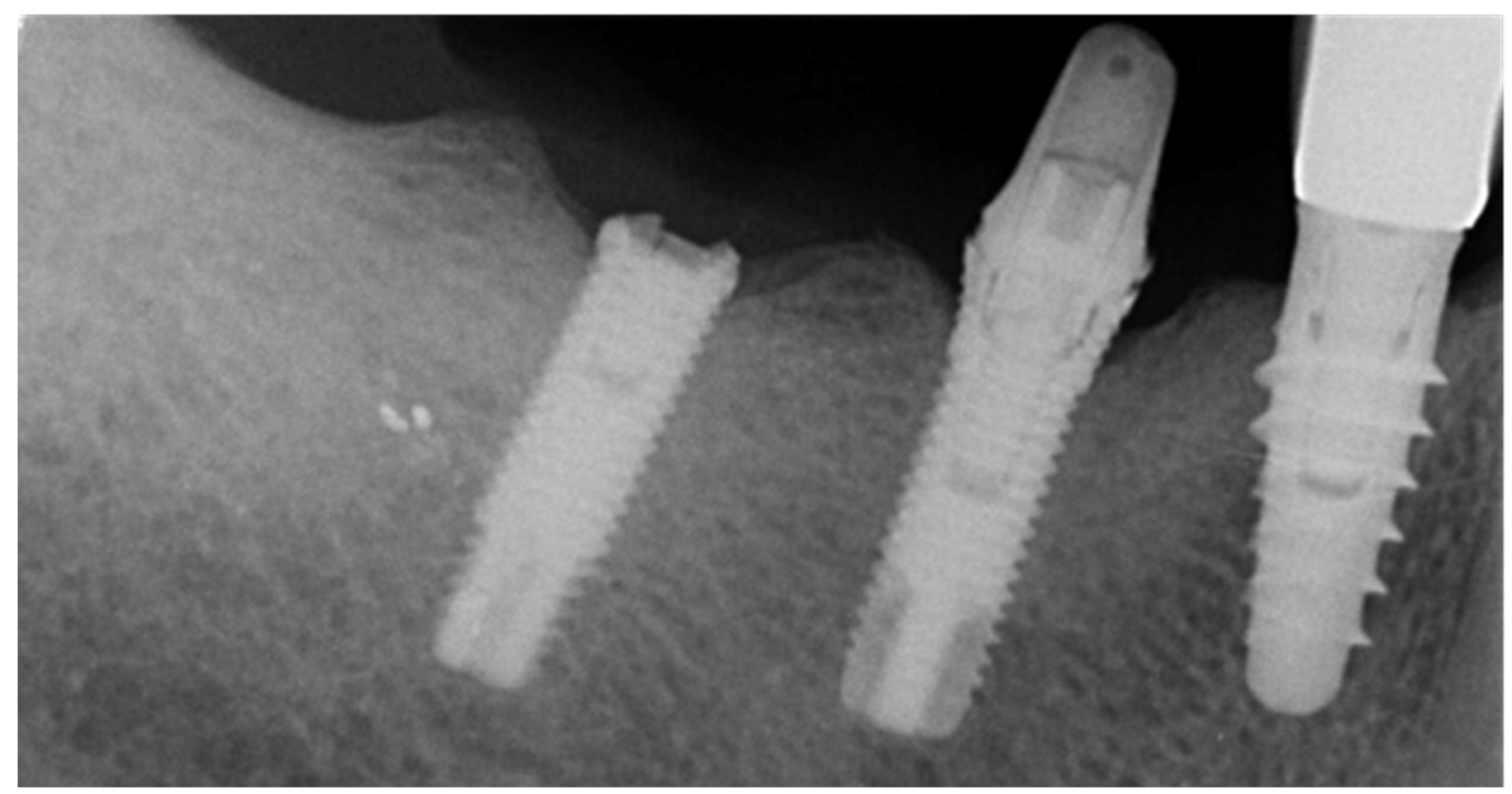

Figure 1. Periapical radiograph of case number one. Two fractured implants in the mandible. Standard $4.0 \mathrm{~mm}$ implants were installed in the molar area. Implants fractured after 10 years on function. Before fracture, screw loosening of abutment screws occurred.

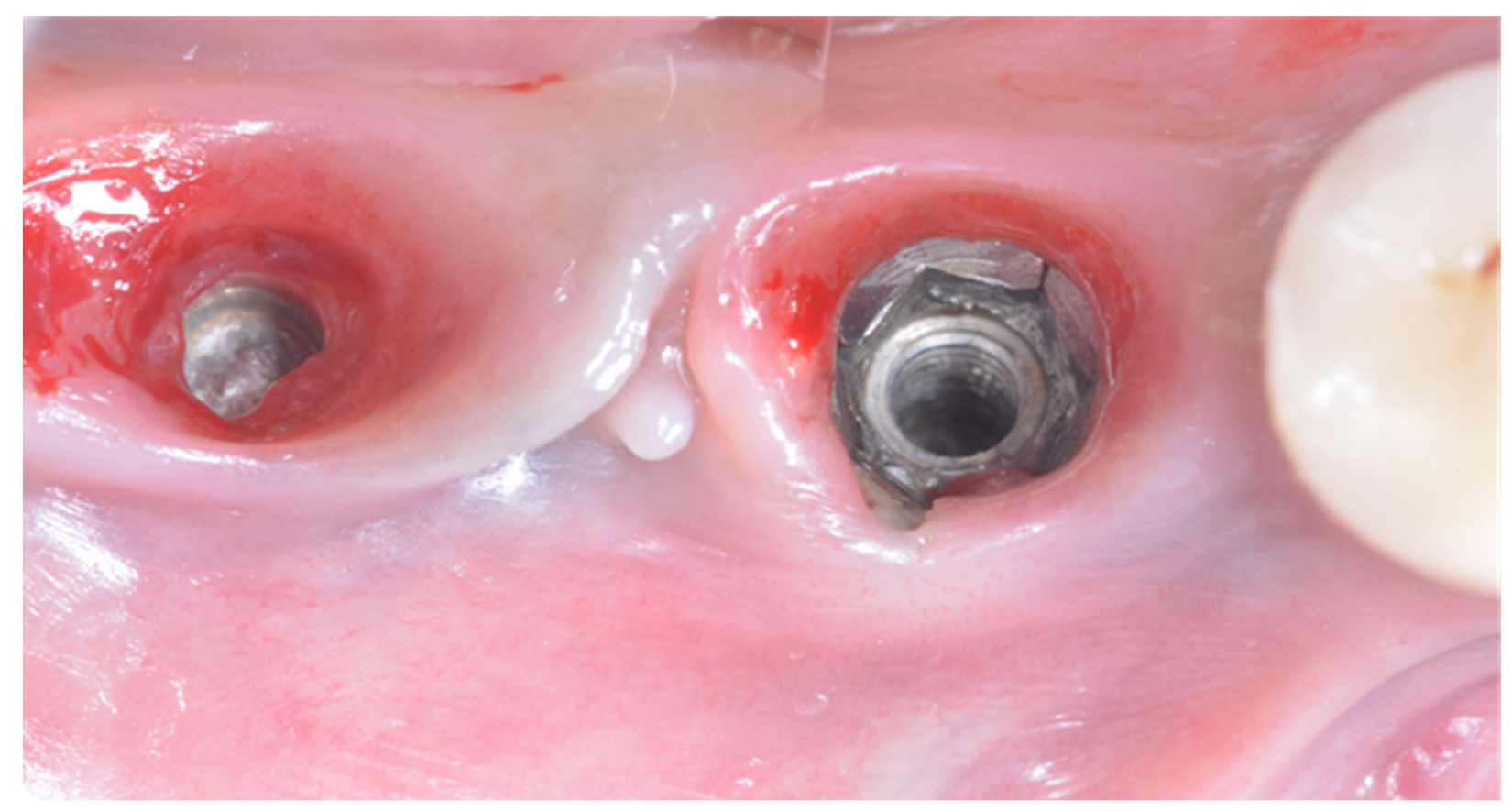

Figure 2. Clinical view of the case number one. 


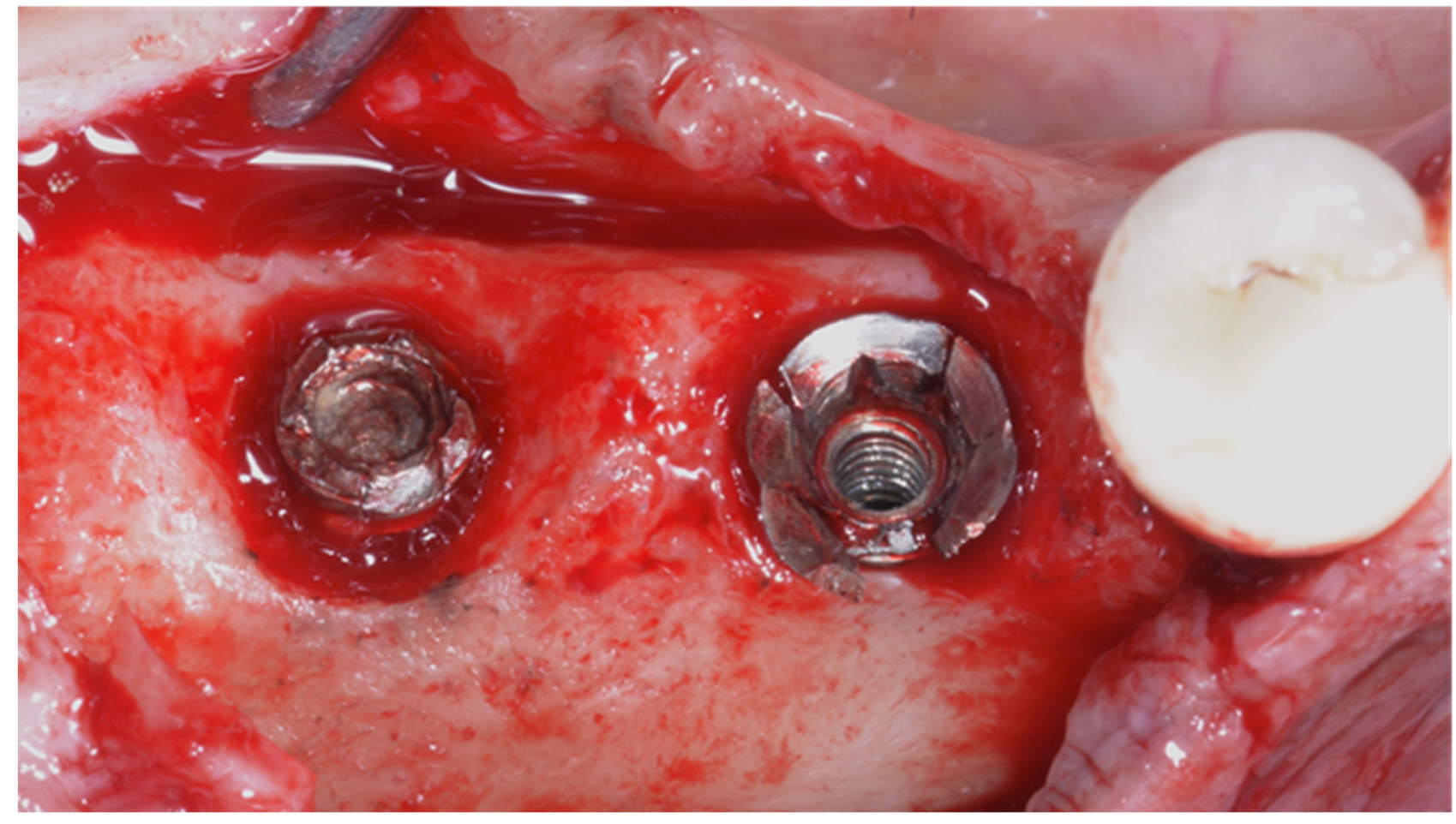

Figure 3. Surgical view of the case number one.

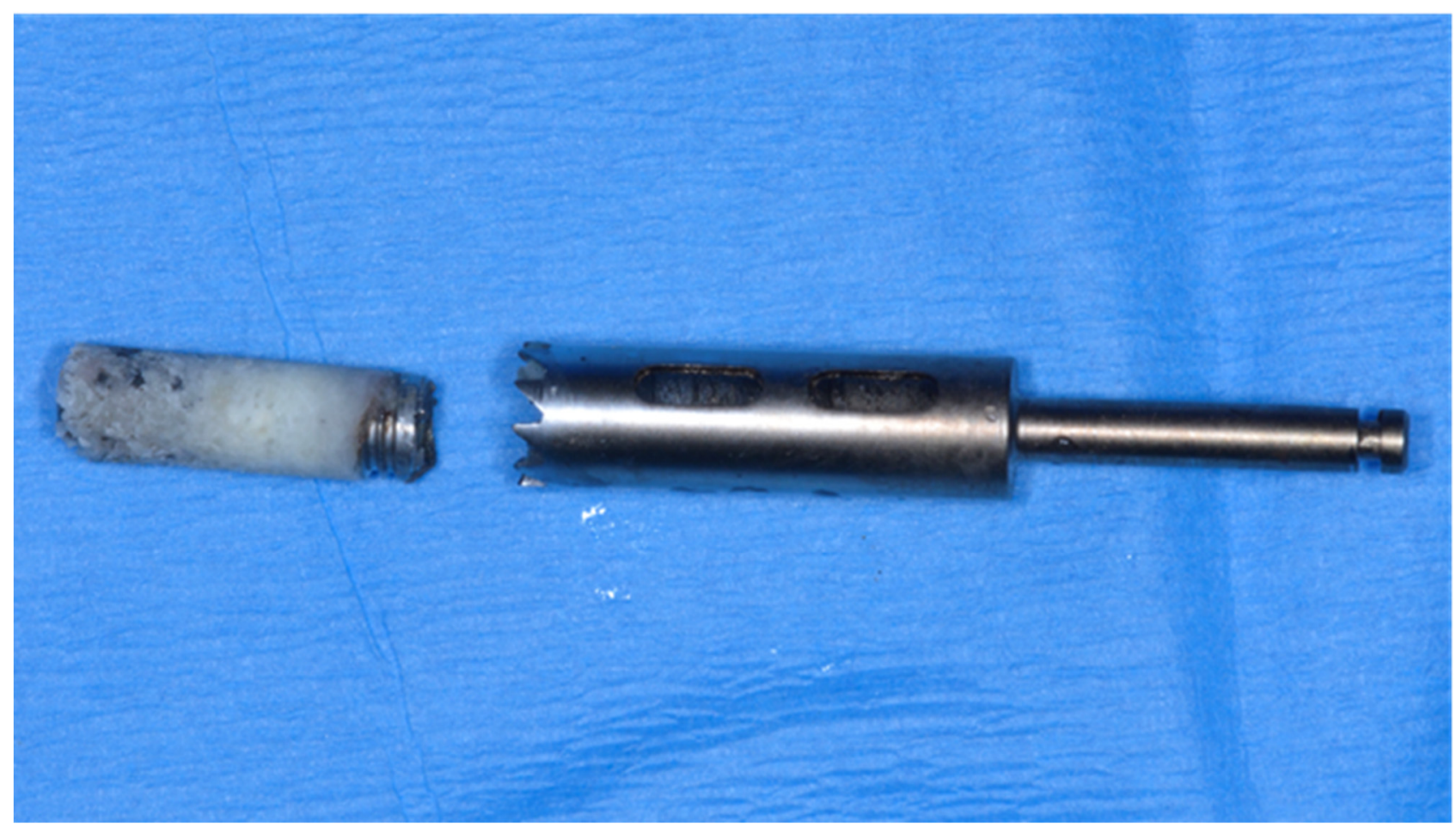

Figure 4. Trephine drill used to remove the fractured implants. 


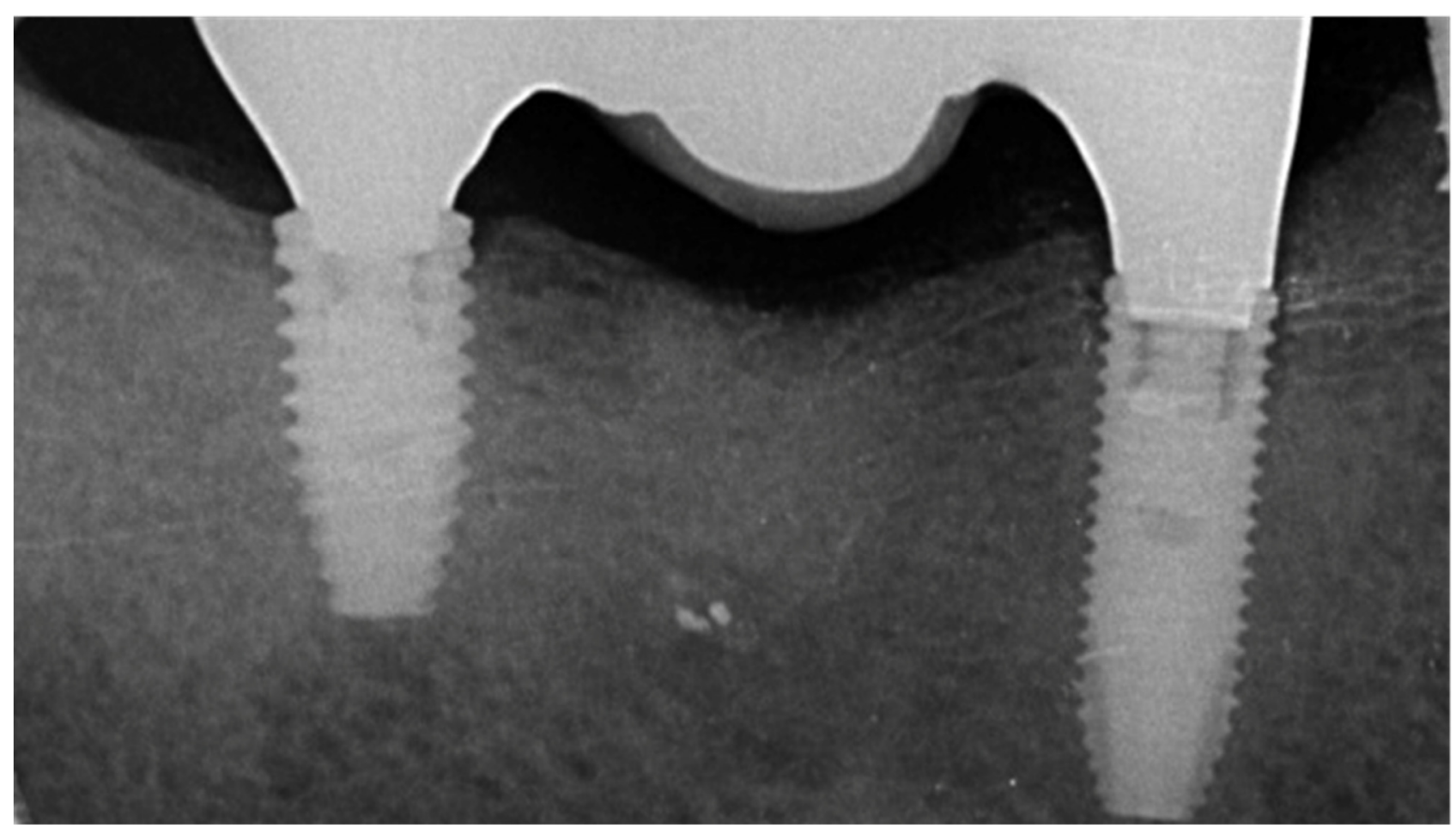

Figure 5. Periapical view of the new prosthetic rehabilitation. New implants were placed in the same day and leaving to heal submerged. Four months later the new restoration was delivered.

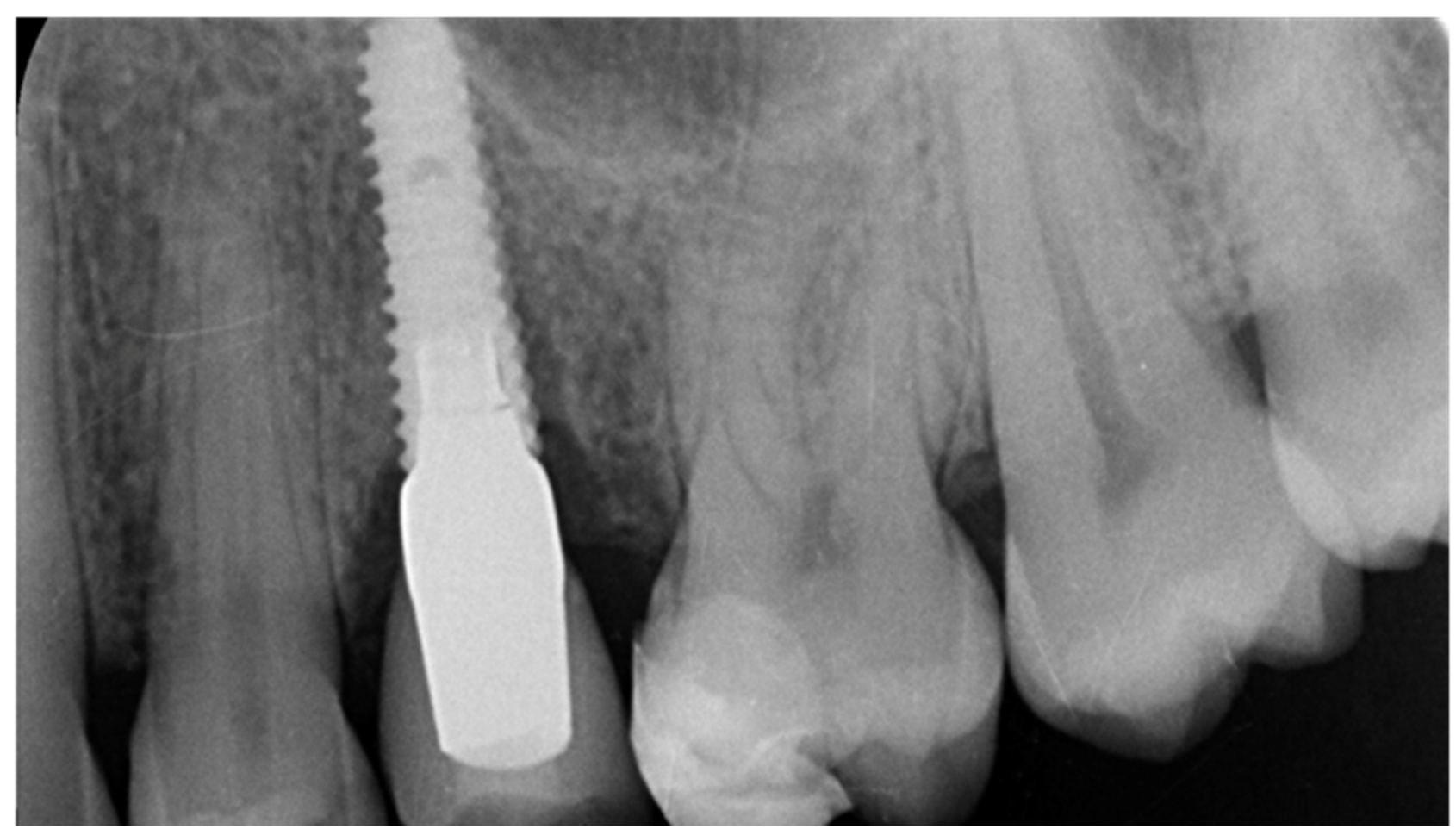

Figure 6. Periapical radiograph of case number two. A $3.5 \mathrm{~mm}$ diameter implant fractured in the maxillary premolar position two years after delivery of the final restoration. Before fracture, screw loosening of abutment screw occurred. 


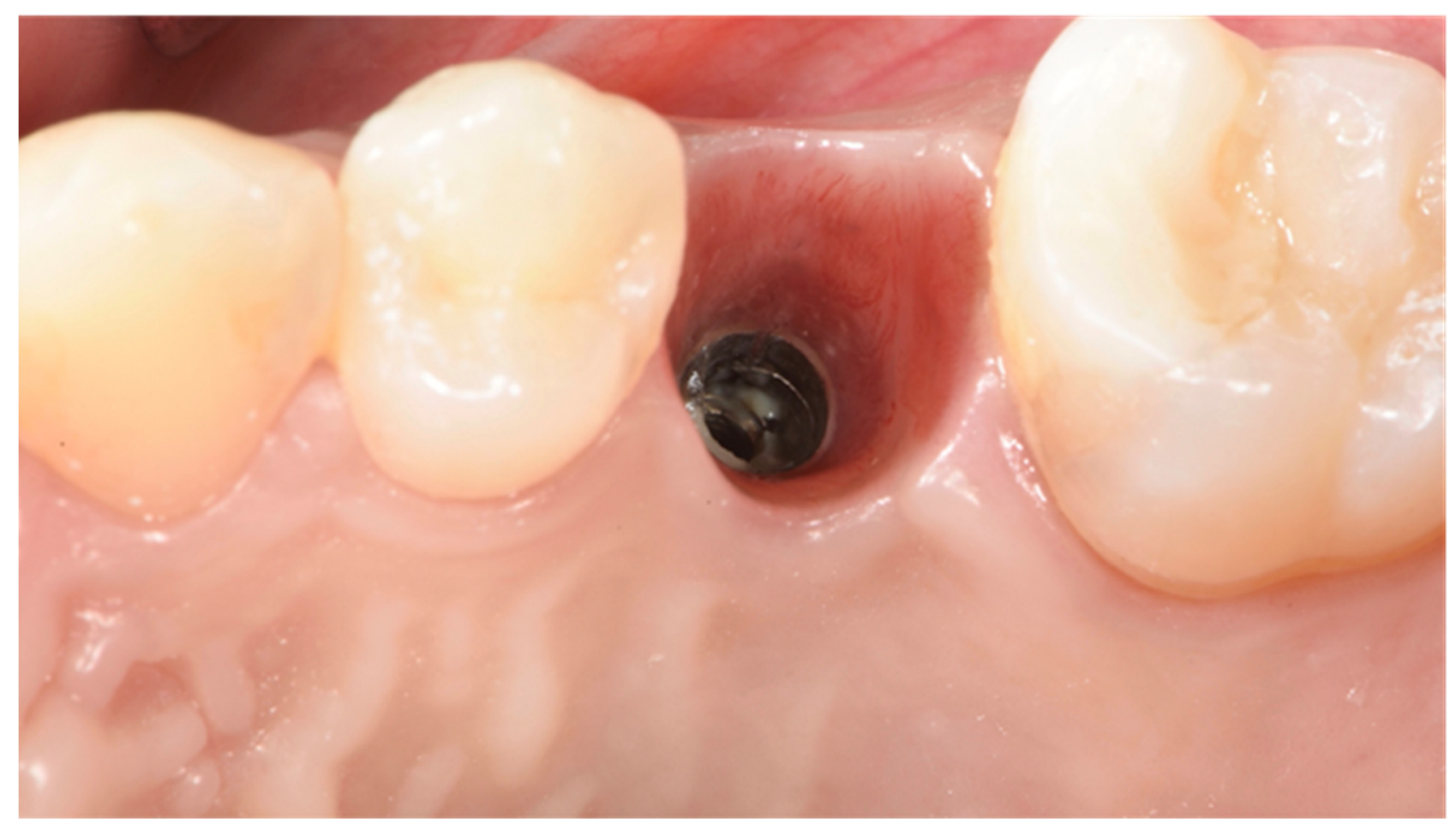

Figure 7. Clinical view of the case number two.

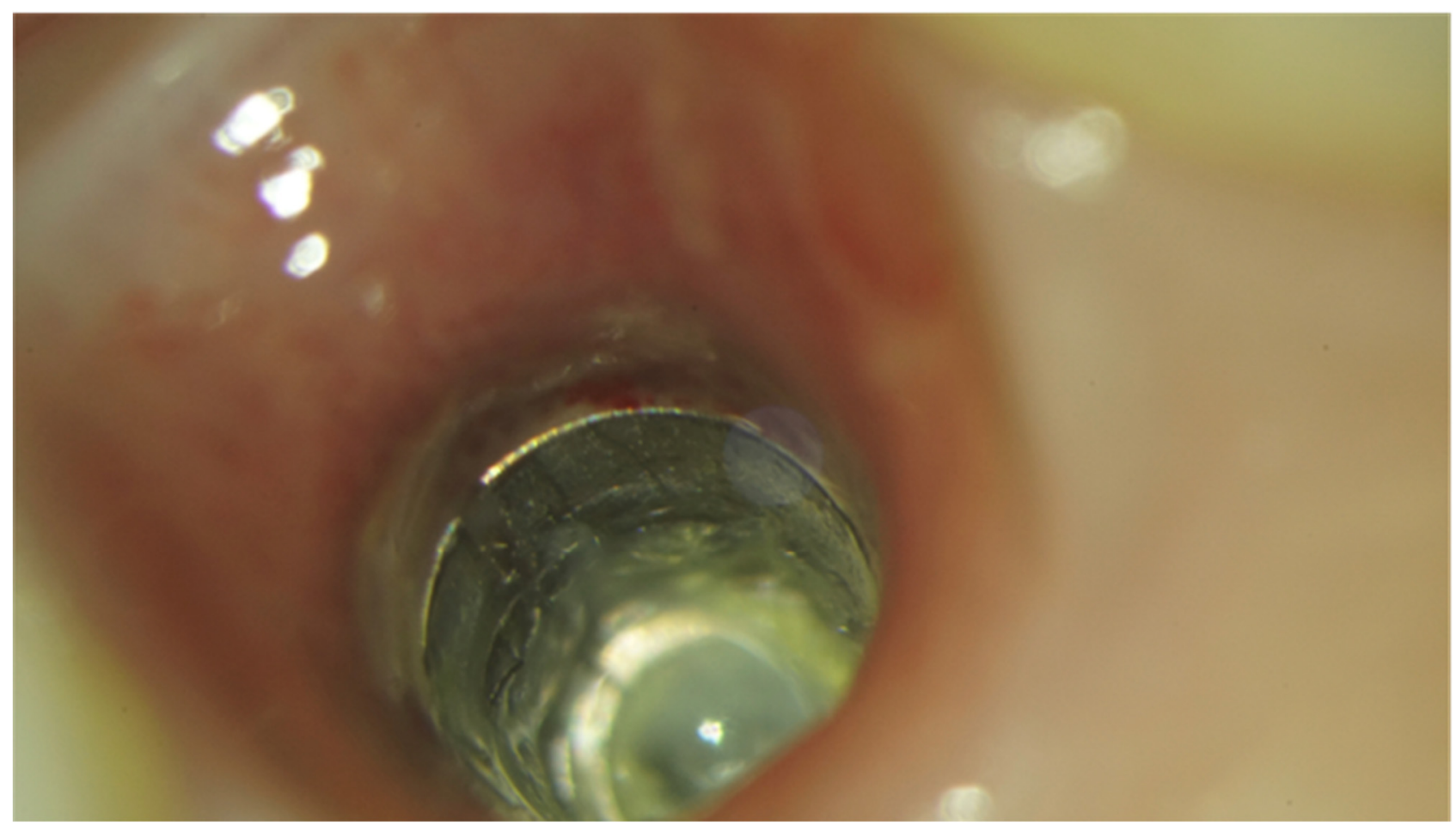

Figure 8. Detail of the case number two at 25X magnification. 


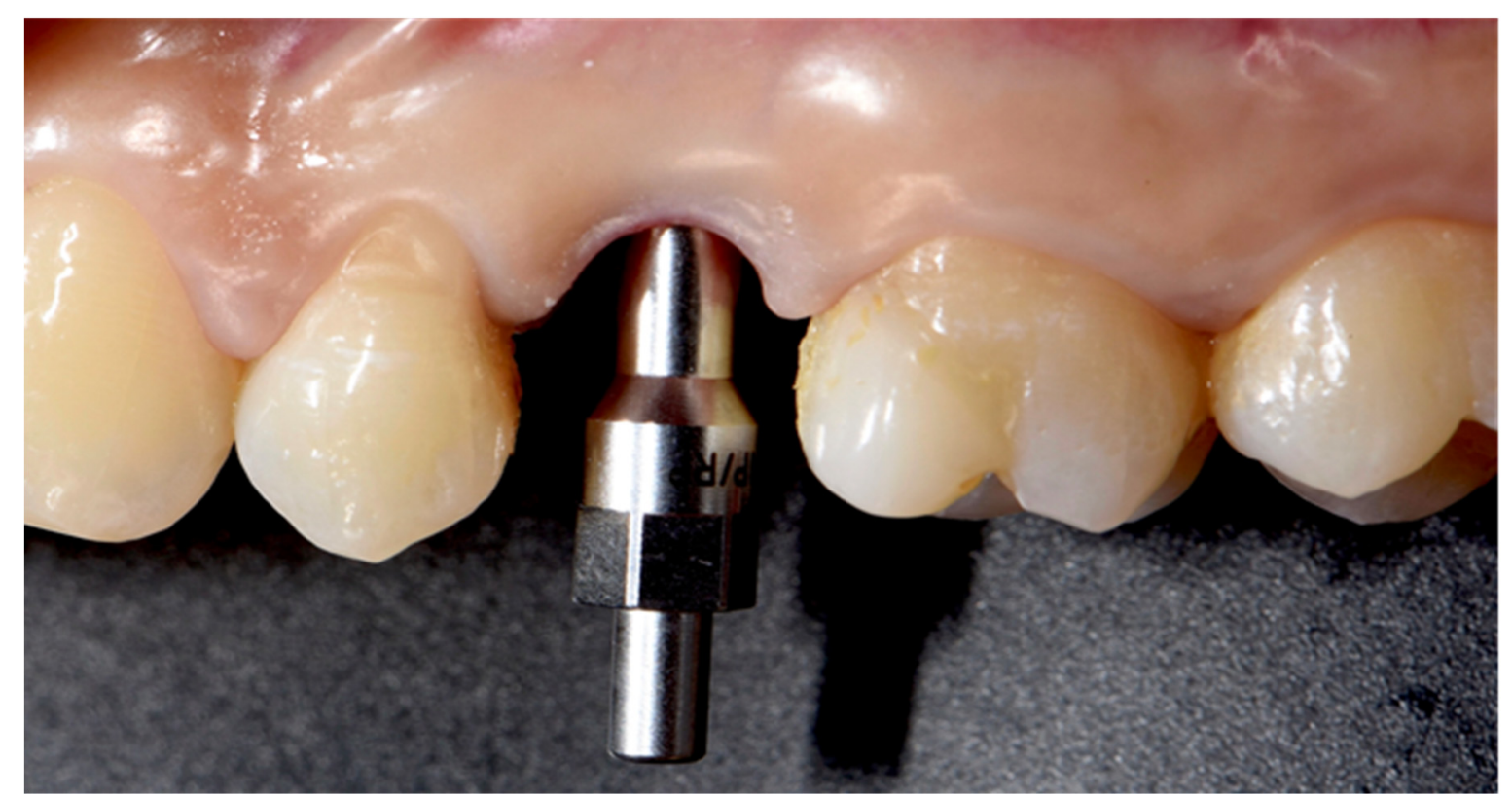

Figure 9. Implant retrieval tool.

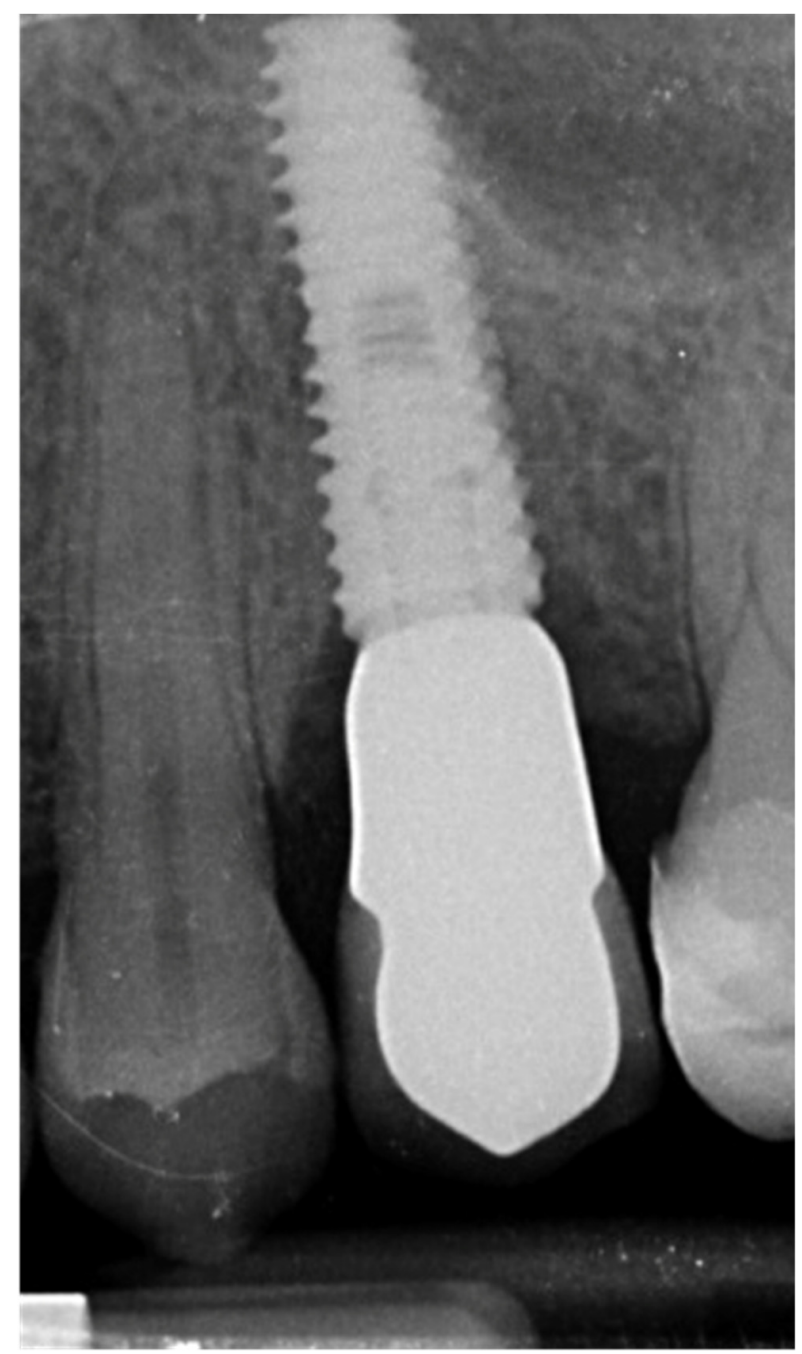

Figure 10. Four months long-term x ray evaluation. No bone resorption is noted. 
The main limitation of the present research is its study design (narrative review). However, a systematic review is not easy to develop. Due to ethical reasons, it is not possible to conduct randomized controlled trial evaluating implants fracture, so, data derived only from retrospective evaluations or previous reviews. Nevertheless, retrospective study could help to find possible risk factors associated to implants fracture, helping to prevent this irreversible complication.

\section{Materials and Methods}

\subsection{Focus Question and Search Strategy}

The focus question of the present narrative review was to evaluate whether there were any possible factors influencing the fracture of dental implants. A literature search strategy encompassing the literature in English from 1967 up to July 2021 was performed to identify relevant studies meeting the inclusion criteria. The PubMed database of the U.S. National Library of Medicine has been consulted using a combination of Boolean keywords including MeSH (Medical Subject Headings), free text terms, and filters with the following combination: Search: ("Dental Implants/adverse effects" [Mesh] AND "fracture") Filters: Abstract, Dental journals, English. Screening was performed independently by two expert examiners (SSM, FMC).

\subsection{Eligibility Criteria}

The following inclusion criteria was defined for the selection of the articles: papers written in the English language; clinical examination of human patients reporting incidence of implant fracture; prospective and retrospective observational studies; systematic reviews; meta-analysis; narrative reviews, and consensus conference. Articles were excluded if they were: animal or in vitro studies; reports with less than 15 patients; reports of implant outcomes with less than one year on function.

\subsection{Data Collection Process}

Full-text papers were obtained for all the selected abstracts and titles that appeared to meet the inclusion and exclusion criteria, and they were assessed for inclusion by the same two reviewers. A final reviewer (MT) evaluated possible inconsistencies between the two reviewers. Moreover, the reference lists of the selected studies were screened for additional papers that could meet the eligibility criteria of this review. Given the narrative nature of this study, no any methodology and reporting quality of selected articles was performed in order to collect the greatest number of manuscripts. Moreover, considering that no randomized controlled trial assessing implants fracture as primary outcome could be conducted due to ethical reasons, systematic approach and meta-analysis could not be done. All the full texts of the selected papers were stored in shared folders accessible to all the reviewers.

\subsection{Measures and Analysis of Results}

The incidence of implants fracture and the risks factors for implants fracture were considered for data analysis. Data from selected manuscript were divided and evaluated to find incidence of implant fracture, and possible risk factors. Chi-square test calculation was performed on-line (https: / / www.socscistatistics.com/tests / chisquare2/default2.aspx) to find any statistically significant difference between risks factors and incidence of implants fracture.

\section{Conclusions}

Implants fracture is a rare but dramatic complication that leads to implants and prostheses failures. Mechanical properties play a key role. The mean implants fracture is $0.52 \%$. To overcame this drawback the prevention is mandatory. Poor implant planning, including implant design and diameter and occlusal overloading, were the most common variables associated with implant fracture. Prevention of marginal bone loss is also important. Further study are needed to confirm this results. 
Author Contributions: Conceptualization, M.T. and M.C.; literature search, Ł.Z. and S.M.M.; writingoriginal draft preparation, review and editing, M.T. and R.S.; supervision, C.-J.P. All authors have read and agreed to the published version of the manuscript.

Funding: This research received no external funding.

Institutional Review Board Statement: Not applicable.

Informed Consent Statement: Not applicable.

Acknowledgments: We would like to thanks Micerium Spa for its support in the Osstem AIC Italy consensus conference.

Conflicts of Interest: The authors declare no conflict of interest.

\section{References}

1. Adell, R.; Lekholm, U.; Rockler, B.; Brånemark, P.I. A 15-year study of osseointegrated implants in the treatment of the edentulous jaw. Int. J. Oral Surg. 1981, 10, 387-416. [CrossRef]

2. AlFarraj Aldosari, A.; Anil, S.; Alasqah, M.; Al Wazzan, K.A.; Al Jetaily, S.A.; Jansen, J.A. The influence of implant geometry and surface composition on bone response. Clin. Oral Implant. Res. 2014, 25, 500-505. [CrossRef]

3. Berglundh, T.; Persson, L.; Klinge, B. A systematic review of the incidence of biological and technical complications in implant dentistry reported in prospective longitudinal studies of at least 5 years. J. Clin. Periodontol. 2002, 29 (Suppl. S3), $197-233$. [CrossRef]

4. Tabrizi, R.; Behnia, H.; Taherian, S.; Hesami, N. What Are the Incidence and Factors Associated With Implant Fracture? J. Oral Maxillofac. Surg. 2017, 75, 1866-1872. [CrossRef]

5. Brånemark, P.I.; Hansson, B.O.; Adell, R.; Breine, U.; Lindström, J.; Hallén, O.; Ohman, A. Osseointegrated implants in the treatment of the edentulous jaw. Experience from a 10-year period. Scand. J. Plast. Reconstr. Surg. Suppl. 1977, 16, 1-132.

6. Velásquez-Plata, D.; Lutonsky, J.; Oshida, Y.; Jones, R. A close-up look at an implant fracture: A case report. Int. J. Periodontics Restor. Dent. 2002, 22, 483-491.

7. Goodacre, C.J.; Kan, J.Y.; Rungcharassaeng, K. Clinical complications of osseointegrated implants. J. Prosthet. Dent. 1999, 81, 537-552. [CrossRef]

8. Chrcanovic, B.R.; Kisch, J.; Albrektsson, T.; Wennerberg, A. Factors influencing the fracture of dental implants. Clin. Implant. Dent. Relat. Res. 2017, 20, 58-67. [CrossRef] [PubMed]

9. Grunder, U.; Gracis, S.; Capelli, M. Influence of the 3-D bone-to-implant relationship on esthetics. Int. J. Periodontics Restor. Dent. 2005, 25, 113-119.

10. Gargallo Albiol, J.; Satorres-Nieto, M.; Puyuelo Capablo, J.L.; Sánchez Garcés, M.A.; Pi Urgell, J.; Gay Escoda, C. Endosseous dental implant fractures: An analysis of 21 cases. Med. Oral Patol. Oral y Cir. Bucal 2008, 13, E124-E128.

11. Tallarico, M.; Luzi, C.; Galasso, G.; Lione, R.; Cozza, P. Comprehensive rehabilitation and natural esthetics with implant and orthodontics (CRANIO): An interdisciplinary approach to missingmaxillary lateral incisors. J. Oral Sci. Rehabil. 2017, 3, 8-16.

12. Reis, T.; Zancopé, K.; Karam, F.K.; Neves, F. Biomechanical behavior of extra-narrow implants after fatigue and pull-out tests. J. Prosthet. Dent. 2019, 122, 54.e1-54.e6. [CrossRef]

13. Tuzzolo Neto, H.; Tuzita, A.S.; Gehrke, S.A.; de Vasconcellos Moura, R.; Zaffalon Casati, M.; Mikail Melo Mesquita, A. A Comparative Analysis of Implants Presenting Different Diameters: Extra-Narrow, Narrow and Conventional. Materials 2020, $13,1888$. [CrossRef]

14. Tallarico, M.; Caneva, M.; Baldini, N.; Gatti, F.; Duvina, M.; Billi, M.; Iannello, G.; Piacentini, G.; Meloni, S.M.; Cicciù, M. Patientcentered rehabilitation of single, partial, and complete edentulism with cemented- or screw-retained fixed dental prosthesis: The First Osstem Advanced Dental Implant Research and Education Center Consensus Conference 2017. Eur. J. Dent. 2018, 12, 617-626. [CrossRef]

15. Sánchez-Pérez, A.; Moya-Villaescusa, M.J.; Jornet-Garcia, A.; Gomez, S. Etiology, risk factors and management of implant fractures. Med. Oral Patol. Oral y Cir. Bucal 2010, 15, e504-e508. [CrossRef] [PubMed]

16. Stoichkov, B.; Kirov, D. Analysis of the causes of dental implant fracture: A retrospective clinical study. Quintessence Int. 2018, 49, 279-286. [CrossRef]

17. Lee, D.W.; Kim, N.H.; Lee, Y.; Oh, Y.A.; Lee, J.H.; You, H.K. Implant fracture failure rate and potential associated risk indicators: An up to 12-year retrospective study of implants in 5124 patients. Clin. Oral Implant. Res. 2019, 30, 206-217. [CrossRef] [PubMed]

18. Available online: www.aaid.com/index.html (accessed on 1 August 2021).

19. Available online: https://www.mordorintelligence.com/industry-reports/dental-implants-market (accessed on 1 August 2021).

20. Canullo, L.; Tallarico, M.; Radovanovic, S.; Delibasic, B.; Covani, U.; Rakic, M. Distinguishing predictive profiles for patient-based risk assessment and diagnostics of plaque induced, surgically and prosthetically triggered peri-implantitis. Clin. Oral Implant. Res. 2016, 27, 1243-1250. [CrossRef] 
21. Cervino, G.; Romeo, U.; Lauritano, F.; Bramanti, E.; Fiorillo, L.; D’Amico, C.; Milone, D.; Laino, L.; Campolongo, F.; Rapisarda, S.; et al. Fem and Von Mises Analysis of OSSTEM ${ }^{\circledR}$ Dental Implant Structural Components: Evaluation of Different Direction Dynamic Loads. Open Dent. J. 2018, 12, 219-229. [CrossRef] [PubMed]

22. Leitão-Almeida, B.; Camps-Font, O.; Correia, A.; Mir-Mari, J.; Figueiredo, R.; Valmaseda-Castellón, E. Effect of crown to implant ratio and implantoplasty on the fracture resistance of narrow dental implants with marginal bone loss: An in vitro study. BMC Oral Health 2020, 20, 329. [CrossRef] [PubMed]

23. Ghazal, S.S.; Huynh-Ba, G.; Aghaloo, T.; Dibart, S.; Froum, S.; O’Neal, R.; Cochran, D. A Randomized, Controlled, Multicenter Clinical Study Evaluating The Crestal Bone Level Change of SLActive Bone Level Ø $3.3 \mathrm{~mm}$ Implants Compared To SLActive Bone Level Ø $4.1 \mathrm{~mm}$ Implants For Single-Tooth Replacement. Int. J. Oral Maxillofac. Implant. 2019, 34, 708-718. [CrossRef] [PubMed]

24. Karl, M.; Krafft, T.; Kelly, J.R. Fracture of a narrow-diameter roxolid implant: Clinical and fractographic considerations. Int. J. Oral Maxillofac. Implant. 2014, 29, 1193-1196. [CrossRef] [PubMed]

25. Pérez, R.A.; Gargallo, J.; Altuna, P.; Herrero-Climent, M.; Gil, F.J. Fatigue of Narrow Dental Implants: Influence of the Hardening Method. Materials 2020, 13, 1429. [CrossRef] [PubMed]

26. Velasco-Ortega, E.; Flichy-Fernández, A.; Punset, M.; Jiménez-Guerra, A.; Manero, J.M.; Gil, J. Fracture and Fatigue of Titanium Narrow Dental Implants: New Trends in Order to Improve the Mechanical Response. Materials 2019, 12, 3728. [CrossRef]

27. Santonocito, D.; Nicita, F.; Risitano, G. A Parametric Study on a Dental Implant Geometry Influence on Bone Remodelling through a Numerical Algorithm. Prosthesis 2021, 3, 16. [CrossRef]

28. D'Amico, C.; Bocchieri, S.; Sambataro, S.; Surace, G.; Stumpo, C.; Fiorillo, L. Occlusal Load Considerations in Implant-Supported Fixed Restorations. Prosthesis 2020, 2, 23. [CrossRef] 